\title{
RANCANG BANGUN SENSOR VISKOSITAS CAIRAN MENGGUNAKAN STRAIN GAUGE DENGAN PRINSIP SILINDER KONSENTRIS
}

\author{
Oleh: \\ Farid Samsu Hananto*
}

\begin{abstract}
ABSTRAK: Viskositas adalah salah satu sifat penting suatu cairan. Pengukuran viskositas kebanyakan dilakukan dengan cara mekanik dan manual. Untuk memudahkan pengukuran dan digitalisasi pengukuran viskositas diperlukan sensor yang bisa mengubah besaran viskositas menjadi besaran listrik.

Dalam penelitian ini telah di rancang sensor viskostas cairan menggunakan strain gauge menggunakan prinsip silinder konsentris. Silinder dalam menggunakan diameter $3 \mathrm{~cm}$ sedangkan silinder luar yang juga berfungsi sebagai tempat cairan sampel berdiameter $4 \mathrm{~cm}$. Silinder dalam dihubungkan dengan pelat pegas oleh sebuah as yang mana pada pegas tersebut dilekatkan sensor strain gauge. Silinder luar sebagai tempat sampel cairan dihubungkan ke sebuah motor yang dapat berputar konstan. Putaran silinder luar ini akan membuat cairan ikut berputar dan juga akan menyeret silinder dalam bergeser memutar. Gaya yang diterima oleh silinder dalam ini salah satunya tergantung pada viskositas dari cairan ini yang nantinya bisa dibaca oleh sensor strain gage yang dilekatkan pada pegas silinder dalam.

Dari hasil penelitian didapatkan data bahwa tegangan keluaran rata-rata untuk sensor ini didapatkan sebesar 1,2 mvolt/cPois. Yang ini berarti setiap 1 cPois viskostas cairan akan menghasilkan tegangan sebesar 1,2 mili volt.
\end{abstract}

Kata Kunci: Sensor, Viskositas, Strain Gauge.

ABSTRACT: Viscosity is one of importants properties of liquid. The measurement commonly used mechanical and manual way. To digitalized and make the measurement easier, it is need a sensor to convert the viscosity into electric signal.

In this research liquid viscosity sensor has been designed by using strain gage with concentric cylinder principle. Inner cylinder was $3 \mathrm{~cm}$ in diameter and the outer silinder was $4 \mathrm{~cm}$ diameter functioned as liquid container. Inner cylinder connected by a rod equipped with flat spring to attach strain gauge on as sensor. Outer cylinder equipped with motor that constantly rotate. Rotation of outer cylinder make liquid in it follow to rotata and dragged the inner cylinder. The drag force will be sensed by the spring and it will be deformed as well as the strain gauge attached on it. The force then converted by strain gauge into voltage.

From the research it was obtained that the average output sensor is $1,2 \mathrm{mvolt} / \mathrm{cPois}$. That meant that for $1 \mathrm{cPois}$ viscosity will generate 1,2 milivolt in voltage.

Keywords: Sensor, Viscosity, Strain Gauge.

\section{PENDAHULUAN}

Viskositas adalah sifat yang penting dari sebuah zat cair. Sistem fisis dan berbagai macam aplikasi dalam aliran dalam pipa, aliran darah, pelumasan komponen-komponen mesin, dinamika curah hujan, lelehan lava gunung berapi, pembentukan medan magnet

\footnotetext{
* Staf pengajar pada Jurusan Fisika Fakultas Sains dan Teknologi UIN Maliki Malang
} 
dalam planet dan bintang, segala macam aliran zat cair dikontrol oleh tingkat viskositas dari cairan tersebut. Viskositas didefinisikan sebagai gesekan internal dari cairan. Sifat mikroskopis dari gesekan internal dalam cairan adalah analog dengan konsep makroskopis mekanika gesekan dalam sistem obyek bergerak pada suatu permukaan yang diam. Energi harus diberikan untuk menghasilkan pergeseran diantara dua benda yang saling menempel yang disebabkan oleh ketidakhalusan permukaan, energi ini juga digunakan untuk mengawali dan menjaga gerakan obyek pada permukaan itu.

Pengukuran viskositas dilakukan dengan banyak cara, diantaranya adalah metode bola jatuh, silinder konsentrik, metode plate and cone, piringan sejajar dan metode kapilaritas [1]. Semua metode diatas menggunakan sistem mekanik dan pembacaannya simpangan juga dalam bentuk mekanik atau analog. Pembacaan analog ini sudah mulai ditinggalkan dan digantikan dengan pembacaan secara digital. Untuk pembacaan digital akan lebih mudah dilakukan apabila besaran sudah berupa besaran listrik. Dalam penelitian ini bertujuan untuk merancang dan membuat alat ukur viskositas zat cair dengan menggunakan strain gage menggunakan prinsip silinder konsentris.

\section{Viskositas Zat Cair}

Viskositas merupakan gaya gesekan antara molekul-molekul yang menyusun suatu fluida, dalam hal ini zat cair dan zat gas. Atau viskositas adalah gaya gesekan internal fluida. Molekul-molekul yang membentuk suatu fluida saling bergesekan ketika fluida tersebut mengalir. Pada zat cair, viskositas disebabkan karena adanya gaya kohesi (gaya tarik menarik antara molekul sejenis). Sedangkan dalam zat gas, viskositas disebabkan oleh tumbukan antara molekul [2].

Fluida yang lebih cair biasanya lebih mudah mengalir, contohnya air. Sebaliknya, fluida yang lebih kental lebih sulit mengalir, contohnya minyak goreng, oli, madu dan lainlain. Hal ini dapat buktikan dengan menuangkan air dan minyak goreng di atas lantai yang permukaannya miring. Pasti air mengalir lebih cepat daripada minyak goreng atau oli. Tingkat kekentalan suatu fluida juga bergantung pada suhu. Semakin tinggi suhu zat cair, semakin kurang kental zat cair tersebut. Minyak goreng yang digunakan untuk menggoreng pada awalnya lebih kental setelah mengalami pemanasan menjadi lebih cair [3]. 


\section{Pengukuran Viskositas Metode Silinder Konsentris}

Instrumen untuk pengukuran viskositas didesain untuk menentukan resistansi fluida untuk mengalir. Mengingat viskositas ini merupakan salah satu parameter mekanik penting, maka alat ukurnya akan sangat berguna. Aliran fluida dapat dimodifikasi dengan membuat dua pelat yang dipisahkan oleh fluida kemudian salah satu pelat dikenakan gaya, atau permukaan itu dapat berupa silinder. Dapat juga dengan menjatuhkan benda di dalam fluida, mengalirkan fluida ke dalam tabung kapiler. Resistansi untuk mengalir diukur sebagai gaya atau torsi atau penurunan tekanan [1].

Keuntungan utama dari prinsip pengukuran viskositas ini dibanding yang lain adalah kemampuannya untuk beroperasi secara kontinyu. Dengan demikian pengukuran dapat dilakukan terus-menerus pada temperatur yang diubah-ubah. Inilah sebab metode ini sering digunakan dalam pengukuran viskositas.

Silinder konsentris biasanya digunakan untuk pengukuran viskositas absolute dimana harus diketahui dengan baik gaya shear dan tekanan. Viskometer rotasi silinder sesumbu (concentric cylinder) dibuat berdasarkan 2 standar, sistem Searle dimana silinder bagian dalam berputar dengan silinder bagian luar diam dan sistem Couette dimana bagian luar silinder yang diputar sedangkan bagian dalam silinder diam. Fluida yang akan diukur ditempatkan pada celah diantara kedua silinder. Persamaan matematis untuk menghitung viskositas diturunkan dari hukum newton tentang aliran viskos [1].

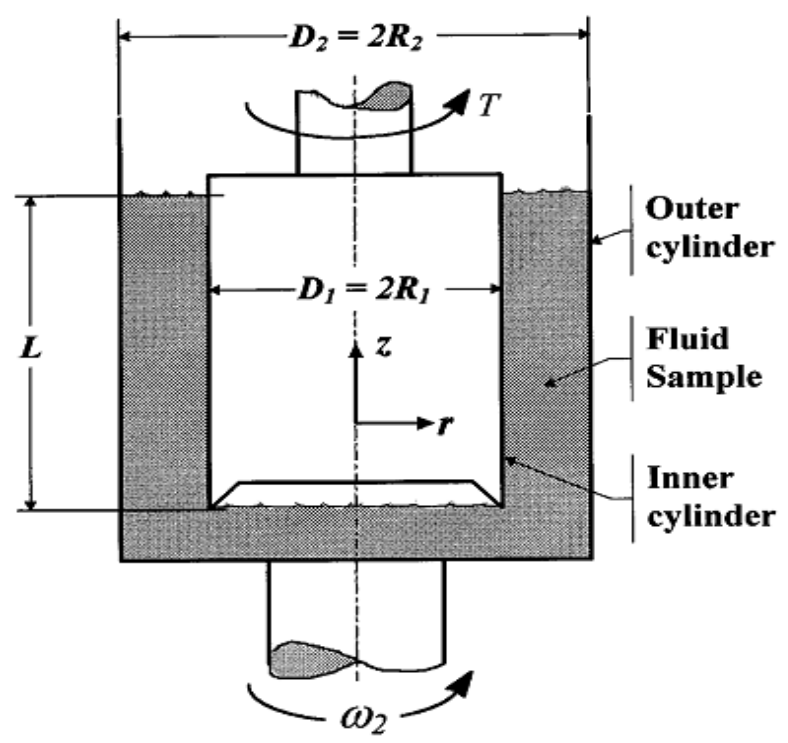

Gambar 1. Skema metode silinder konsentris.

Viskometer silinder konsentris ditunjukkan dalam Gambar 1 terdiri dari dua silinder satu sumbu dengan fluida diantara keduanya. Silnder bagianluar diputar dan torsi diukur 
pada silinder bagian dalam. Jika: $r_{i}=$ jari-jari silinder dalam; ro= jari-jari silinder luar; $\mathrm{L}=$ panjang silinder; $\mathrm{C}=$ radial clearence; $\omega=$ kecepatan sudut putaran maka berdasar hukum newton dapat dituliskan:

$$
F \quad=\eta \mathrm{A} \frac{u}{C}
$$

Dimana A adalah luas area $\left(2 \pi r_{0} L\right)$

$\mathrm{u}=$ kecepatan linier $\left(\mathrm{r}_{\mathrm{o}} . \omega\right)$

$$
F=\eta\left(2 \pi r_{o} L\right) \frac{r_{o} \omega}{C}
$$

Sehingga torsi (T) pada silinder dalam adalah

$$
\mathrm{T}=\mathrm{F} \cdot \mathrm{r}_{\mathrm{i}}=\frac{2 \pi \eta r_{o}{ }^{2} r_{1} L \omega}{C}
$$

\section{Strain Gage}

Ketika sebuah gaya luar dikenakan pada obyek yang diam, maka akan menghasilkan tegangan dan regangan (stress dan strain). Tekanan didefinisikan sebagai gaya lawan obyek sedangkan strain adalah displacement dan deformasi yang terjadi. Untuk sebuah sebuah gaya internal yang uniform, stress (tegangan) dapat dihitung dengan membagi gaya yang diberikan (F) dengan luasan (A) (Gambar 2)[4]

$$
\operatorname{Stess}(\sigma)=\frac{F}{A}
$$

Strain (regangan) didefinisikan sebagai besarnya deformasi tiap satuan panjang sebuah obyek yang dikenai gaya. Strain dihitung dengan membagi perubahan panjang $(\Delta \mathrm{L})$ dengan panjang awal (L)

$$
\text { Strain }(\varepsilon)=\frac{\Delta L}{L}
$$

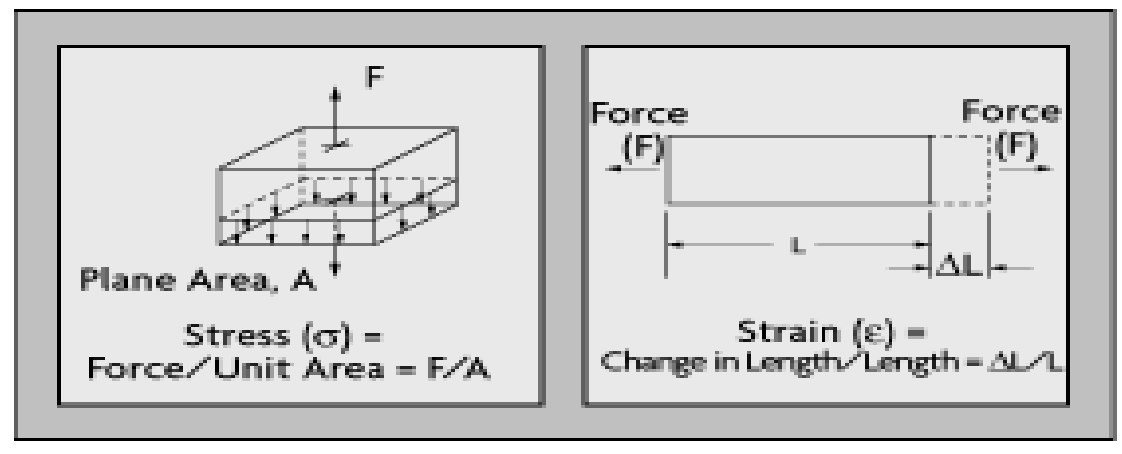

Gambar 2. Definisi Stress dan Strain 
Untuk mengukur strain ini salah satu sensor yang sering digunakan adalah strain gage. Strain gage merupakan susunan filamen tahanan (resistor) yang dibuat sedemikian rupa sehingga membentuk lembaran tipis dengan tebal sekitar 0,025 mm. Sensor ini dapat ditempel langsung pada benda yang diukur strainnya. Gambar strain gage ditunjukkan dalam Gambar 3[5]

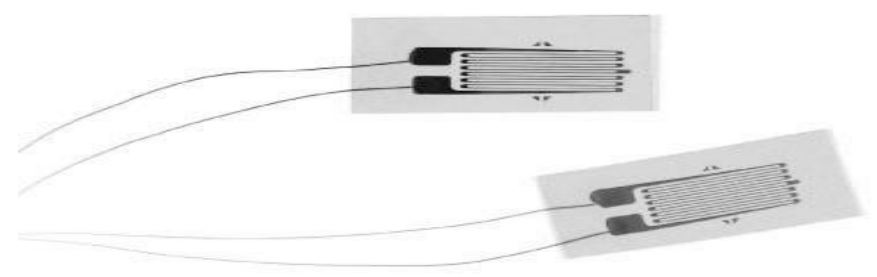

Gambar 3. Strain Gage

Aplikasi strain gage ini sering menggunakan jembatan Wheatstone. Tegangan keluaran jembatan Wheatstone diekspresikan dalam milivolt per volt. Jembatan wheatstone ini juga cocok digunakan untuk kompensasi temperatur. Rangkaian jembatan Wheatstone ditunjukkan dalam gambar 4.

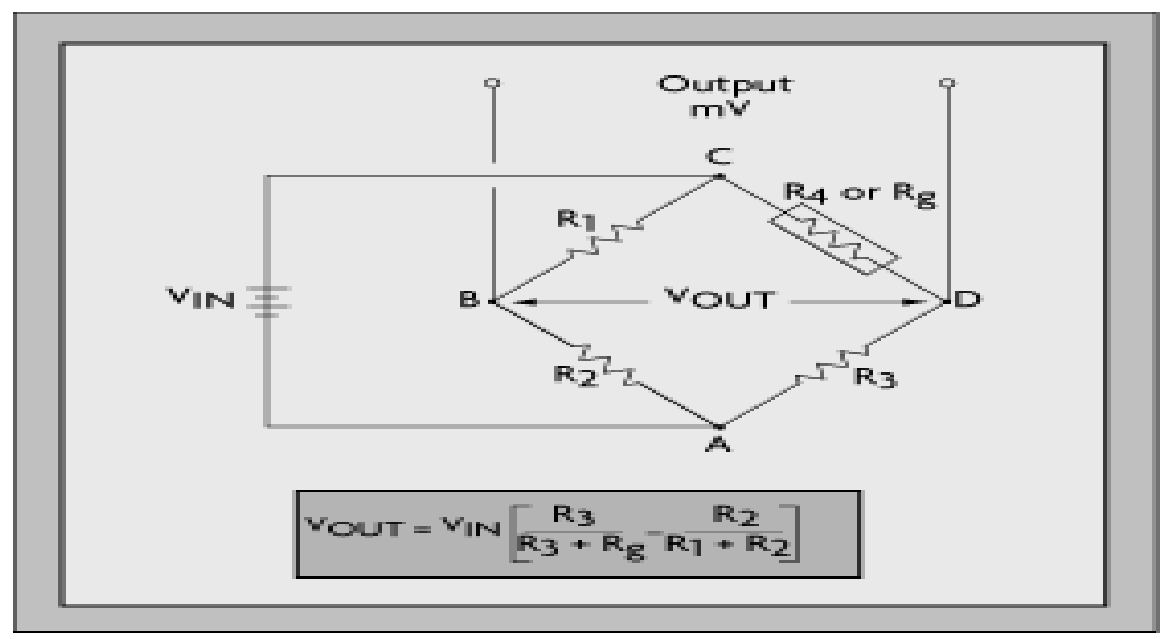

Gambar 4. Rangkaian Jembatan Wheatstone

Dalam gambar 4 , bila $R_{1}, R_{2}, R_{3}$ dan $R_{4}$ sama nilainya, dan $V_{\text {in }}$ diberikan pada titik $A$ dan $\mathrm{C}$, maka keluaran pada titik $\mathrm{B}$ dan $\mathrm{D}$ akan nol karena tegangan titik $\mathrm{B}=$ tegangan titik $\mathrm{D}$ sehingga dikatakan jembatan dalam keadaan seimbang. Bila $\mathrm{R}_{4}$ berubah maka jembatan tidak lagi seimbang, sehingga akan ada perbedaan tegangan antara titik B dan D.

\section{HASIL DAN PEMBAHASAN}

Sepuluh sampel oli dengan viskositas yang bervareasi kemudian digunakan untuk menguji sensor yang telah dibuat. Hasil pengujian ditunjukkan pada tabel 1. 


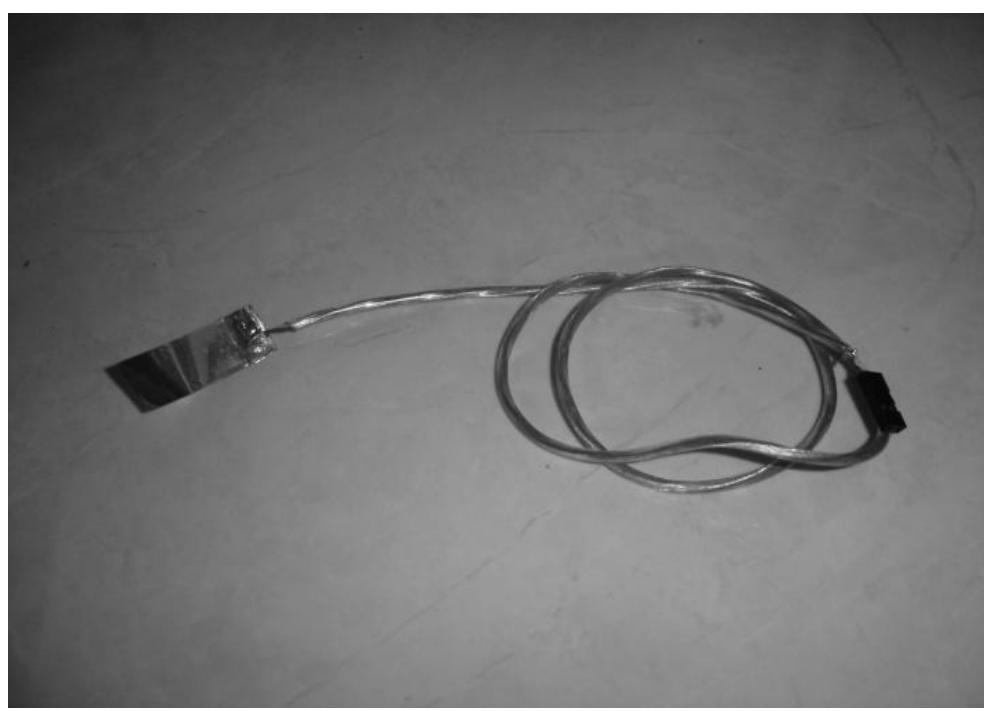

Gambar 5. Sensor Stain gague

Tabel 1. Hasil pengujian PVDF dan Strain Gage

\begin{tabular}{|c|c|c|c|}
\hline \multirow{2}{*}{ Kode } & S:O & Visko & $\begin{array}{c}\text { Tegangan } \\
\text { keluaran } \\
\text { (volt) }\end{array}$ \\
\hline SO0 & $10: 00$ & 3 & SG \\
\hline SO1 & $9: 01$ & 4 & 0,12 \\
\hline SO2 & $8: 02$ & 6 & 0,12 \\
\hline SO3 & $7: 03$ & 17 & 0,12 \\
\hline SO4 & $6: 04$ & 30,2 & 0,13 \\
\hline SO5 & $5: 05$ & 52 & 0,14 \\
\hline SO6 & $4: 06$ & 76 & 0,15 \\
\hline SO7 & $3: 07$ & 110 & 0,18 \\
\hline SO8 & $2: 08$ & 176 & 0,21 \\
\hline SO9 & $1: 09$ & 255 & 0,30 \\
\hline
\end{tabular}




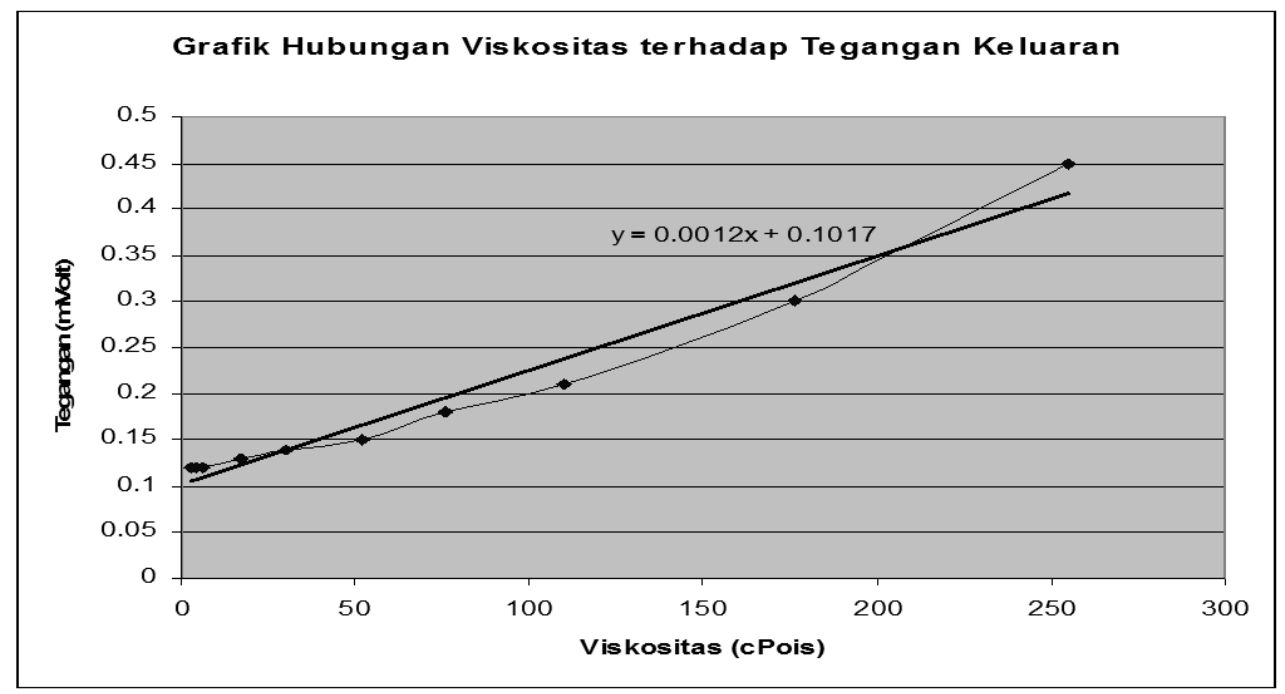

Gambar 6. Grafik keluaran sensor

Perbandingan solar dengan oli akan menyebabkan perbedaan viskositas. Disini digunakan solar yang lebih encer untuk mengurangi viskositas sampel. Semakin tinggi perbandingan solar dengan oli menunjukkan jumlah solar yang lebih banyak yang artinya juga kekentalan sampel menurun. Dalam Tabel 1 terlihat bahwa semakin rendah nilai perbandingan solar dengan oli didapat nilai viskositas makin tinggi, menunjukkan bahwa kepekatan/kekentalan sampel meningkat. Kenaikan viskostas sampel menghasilkan kenaikan tegangan keluaran dari sensor strain gauge. Dikatakan bahwa keluaran sensor berbanding lurus dengan kekentalan sampel.

Dari grafik dapat dilihat bahwa semakin tinggi viskositas maka tegangan yang dihasilkan juga semakin naik. Dengan membuat regresi linier dari grafik didapatkan persamaan $\mathrm{Y}=0,0012 \mathrm{X}+0.1017$

Sehingga dari hasil regrasi didapatkan kepekaan sensor yang dibuat adalah $1,2 \frac{m v}{c P o i s}$, yang artinya adalah setiap kenaikan 1 cPois viskositas akan menaikkan tegangan sebesar 1,2 mvolt.

\section{KESIMPULAN}

Dari penelitian ini dapat disimpulkan bahwa:

1. Rancangan sensor dalam penelitian dapat digunakan untuk melakukan pengukuran viskositas, walaupun tanggapan bukan berupa garis lurus namun dapat didekati dengan regresi.

2. Kepekaan sensor yang dibuat adalah 1,2 mvolt/cPois. 


\section{UCAPAN TERIMAKASIH}

Penulis mengucapkan terimakasih kepada semua pihak yang telah membantu terlaksananya penelitian ini.

\section{DAFTAR PUSTAKA}

[1] Webster, John G. 1999, The Measurement, Instrumentation and Sensors Handbook, CRC Press.

[2] Giancoli, D. C., 2001, Fisika Jilid I (terjemahan), Jakarta : Penerbit Erlangga

[3] David B., 1994, Rheology Modifier Handbook Practical Use and Applications, William Andrew Publishing, New York.

[4] William D. C, 1993. Instrumentasi Elektronik dan Teknik Pengukuran. Erlangga, Jakarta;

[5] Wilson, John, 2005. Sensor Technology Handbook. Elsevier Inc. UK 